\title{
Short Circuit and Recovery Time Tests in a helical bifilar R-SFCL module
}

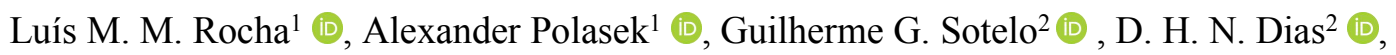 \\ Bruno S. M. C. Borba ${ }^{2}$ (i), David P. Fernandes ${ }^{2}$ (i) \\ ${ }^{I}$ Electric Power Research Center (CEPEL), Rio de Janeiro, Brazil. Postal address: 354 Horácio Macedo \\ Avenue, Cidade Universitária, Ilha do Fundão, Rio de Janeiro, RJ, ZIP code: 21941-911, \\ luismicahel@gmail.com,polasek@cepel.br \\ ${ }^{2}$ Department of Electrical Engineer, Fluminense Federal University, Niterói, Brazil. Postal address: 156 Passo \\ da Pátria Street,São Domingos, Niterói,RJ, ZIP code: 24210-240,gsotelo@id.uff.br,dhndias@id.uff.br, \\ bborba@id.uff.br,davidf@id.uff.br
}

\begin{abstract}
Superconducting Fault Current Limiter (SFCL) modules with distinct arrangements have been investigated, seeking design and performance enhancements. In this context, this work aims to propose a design for resistive SFCL (R-SFCL) modules, using RE-Ba-Cu-O high-temperature superconducting tapes (HTS) wound on an alternative support material. An R-SFCL bench prototype was designed for $400 \mathrm{~A}$ and $500 \mathrm{~V}$. Two pieces of $2 \mathrm{G}$ tapes, arranged in a bifilar antiparallel configuration were wound on Acrylonitrile Butadiene Styrene (ABS) tubes, which were made by means of a 3D printer. During the experiments, the SFCL was immersed in an open bath cryostat with liquid nitrogen and several measurements were carried out. The average limited current is about three times lower than the prospective one. To test the SFCL recovery time, the following procedure was adopted: The fault is induced during three cycles, and after, the current is reduced to zero. The SFCL is reconnected after some time considering that the fault was extinct, and the voltage level returned to normal operation. The results showed promising levels of limitation and recovery time for further developments.
\end{abstract}

Index Terms - RE-Ba-Cu-O HTS tapes, R-SFCL, Short-circuit, 3D printer.

\section{INTRODUCTION}

Increases in electricity demand and the growing importance of distributed generation in power systems have risen concerns about fault current levels [1]. Currently, superconducting fault current limiters (SFCL) have drawn attention as one of the most promising ways to limit fault currents [2], [3], [4]. The SFCL keep approximately zero impedance under normal conditions of the power system, whereas it provides high impedance when leaving the superconducting state (quench), at the fault occurrence [1], [5]-[7].

The SFCL can be categorized into a resistive type, inductive type, and hybrid type devices. Due to its simple topology, compactness, and stability, when compared with other designs, the resistive-type SFCL (R-SFCL) stand out as being the most studied configuration [8]-[10].

Several R-SFCL prototypes have been investigated and developed considering different types of configurations and materials [11]-[13]. Some studies use these prototypes to measure electrical and 
thermal data, such as losses [14], quench and recovery time [15]-[17], temperature, isolation and cryogenic system [18], [19].

For practical application, the use of high-temperature superconductors (HTS) has been widely investigated in the development of real-scale R-SFCL prototypes [20], [21], applicable at the voltage and current levels of the electric power distribution networks.

This paper presents an alternative R-SFCL module with RE-Ba-Cu-O superconducting tapes, using a helical bifilar [22] construction to minimize the total inductance effect from the system assembled on ABS tubes.

Short-circuit tests were performed to the prototype. In addition, an analysis of recovery time was carried out. The results are promising, enabling future developments of the proposed R-SFCL module.

\section{SFCL DESIGN AND FABRICATION}

\section{A. HTS Wire Specification}

The prototype was built with an SF12100-CF Superpower second-generation (2G) tape with a minimal critical current of 297 A (@77 K), as informed by the manufacturer [23]. Moreover, this 2G tape presents a total thickness of $100 \mu \mathrm{m}$ with a thicker substrate layer of $50 \mu \mathrm{m}$ presenting a highly resistive characteristic, suitable for the FCL development. The width of the tape is $12 \mathrm{~mm}$ and a model without the copper stabilizer was used.

\section{B. SFCL Module Arrangement}

The R-SFCL module is composed of two concentric cylindrical hollow components. Each component has a superconductor coil in helical disposal, and the two coils are connected in a series association. To obtain double current capacity, each one of the cylindrical components was designed, and built, with two segments of superconducting tape in parallel helical disposal. Knowing that each segment allows the passage of only 297 A, and assuming an equal split of the current, each path will conduct about $200 \mathrm{~A}$ on normal operation. Fig. 1 represents the superconductor coils helical disposal.

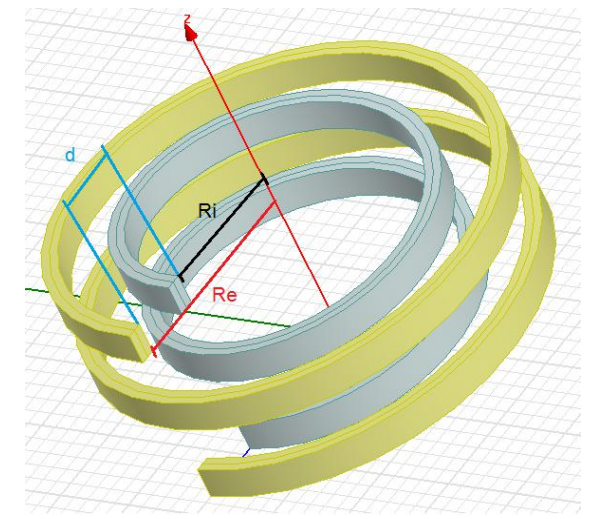

Fig. 1. The superconductor coils in helical bifilar disposal.

Each tube was manufactured with a 3D printer employing Acrylonitrile Butadiene Styrene (ABS). Fig. 2 shows a schematic of these components before assembly. 


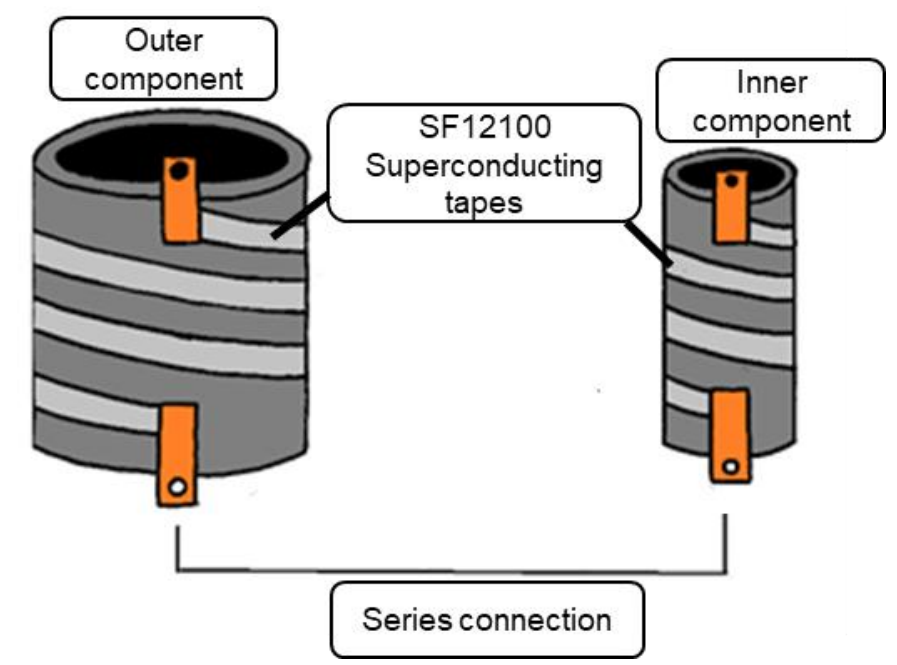

Fig. 2. ABS based tube made with a 3D printer.

The two components were concentrically and electrically connected, to be assembled in a way to reduce the inductance effect at the final impedance value of the R-SFCL, during normal operation.

The junction process between the superconducting tape and the regular terminal conductors will be addressed in the next section. Fig. 3 shows the final assembly with the two main components.

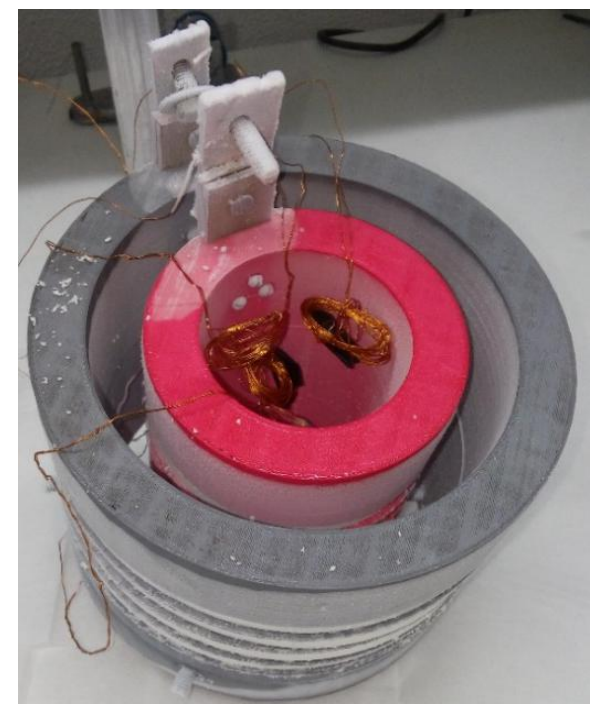

Fig. 3. R-SFCL assembled with the superconducting coils and the copper terminals. Also, it's possible to glance at the measurement terminals.

\section{Soldering HTS tapes to current leads}

The joining process between the superconductor tapes and the copper terminals needs to follow a specific procedure if the goal is to achieve minimal electrical resistance [24], [25]. First, the end of each superconducting tape is attached to a copper terminal, putting the superconducting side connected to the terminal, and the contact surface area is $1.8 \mathrm{~cm}^{2}$. Next, each surface is tinned with a tin-indium alloy at $200{ }^{\circ} \mathrm{C}$, which does not damage the tape. Before the next step, the set was warmed up, by a heat blower, until $200{ }^{\circ} \mathrm{C}$ to melt the alloy, and then joining the two surfaces together 
applying pressure manually on them. After binding the set, the heat source is turned off. Finally, one minute later the pressure is removed. Fig. 4 shows a simple schematic diagram of this process.

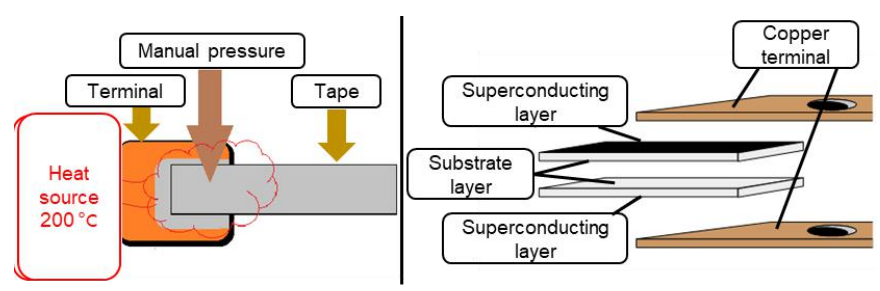

(a)

(b)

Fig. 4. (a) Soldering superconducting tape to the copper terminal; (b) A better view of the superconducting tapes and the copper terminals connection.

At these conditions, the junction shows low electrical resistance, of about $2 \mu \Omega$, and good mechanical resistance during thermal cycles. Fig. 5 presents the inner component soldering process of only one of the tapes connected to the copper terminal.

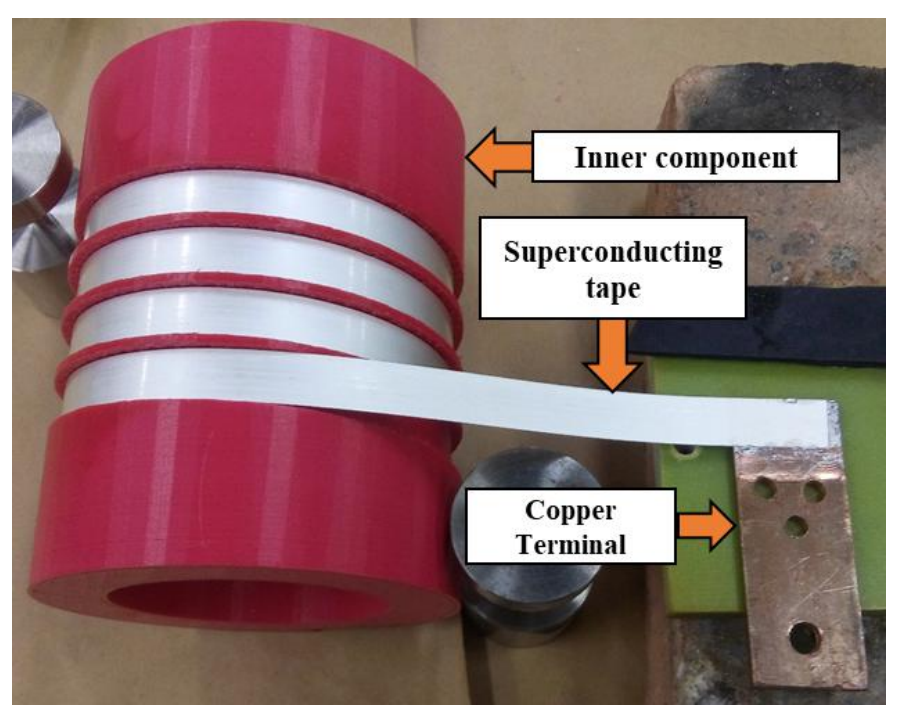

Fig. 5. Internal component soldering process.

\section{EXPERIMENTAL SETUP}

The short-circuit tests as well as the recovery time analysis, were performed with a controlled voltage source $(3 \mathrm{kVA} / 300 \mathrm{~V})$ with a maximum current of $15 \mathrm{~A}$. To reach the desired fault current levels a step-down voltage transformer was employed to increase the current on the secondary terminal. Besides, one nanovoltmeter, an oscilloscope, and a direct current source were used to find the I versus $\mathrm{V}$ behavior. The tests procedures will be addressed in the next sections.

\section{A. IxV Characterization System}

This analysis has the goal to find the total critical current $\left(I_{c}\right)$ of the superconducting tapes connected in parallel. Now that, to determine $I_{c}$, the $\mathrm{IxV}$ characteristic curve was built by empirical analysis. The measurement apparatus is composed by a DC source Argantix KDC 30500, and a Keithley 2182A nanovoltmeter. Further, for both controlling the measurement system and finishing the data acquisition an algorithm was created. Finally, each superconducting module was immersed in 
a liquid nitrogen bath (LN2)@ 77 K.

First, to begin the experiment, the four-point method is applied, to the tapes, to get rid of errors concerning the contacts resistances [24]. Secondly, the measuring system injects square current pulses (400 ms), with an interval of ten seconds, gradually increasing the current form one pulse to the following one. The measured voltage is divided by the distance between the voltage terminals, which is the length of each tape. The current source is automatically turned off if the electrical field is above the critical point $(1 \mu \mathrm{V} / \mathrm{cm})$. Fig. 6 illustrates the experimental setup for the described process.

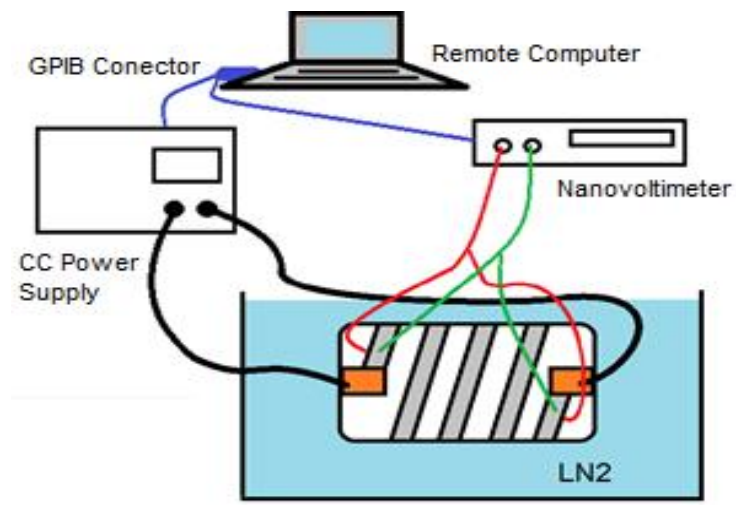

Fig. 6. Schematic of Experimental Setup for IxV Characterization Test.

In the end, the critical current measured in this way corresponds to be the tape in parallel with the lower $I_{c}$ value.

\section{B. Short-circuit and Recovery Time Test System}

The short-circuit, and recovery time test schematic was assembled similarly to previous works [16], [26]. Also, it is shown in detail in Figure 7. Moreover, as previously mentioned, an AC voltage source (Chroma 6512) was connected to a transformer to reach the desired electrical current level. In addition, the measurement was carried out by an oscilloscope Tektronix THS3000 and a Rogowski coil, with the scales of $300 \mathrm{~A}-500 \mathrm{mV} / 3000 \mathrm{~A}-500 \mathrm{mV}$.

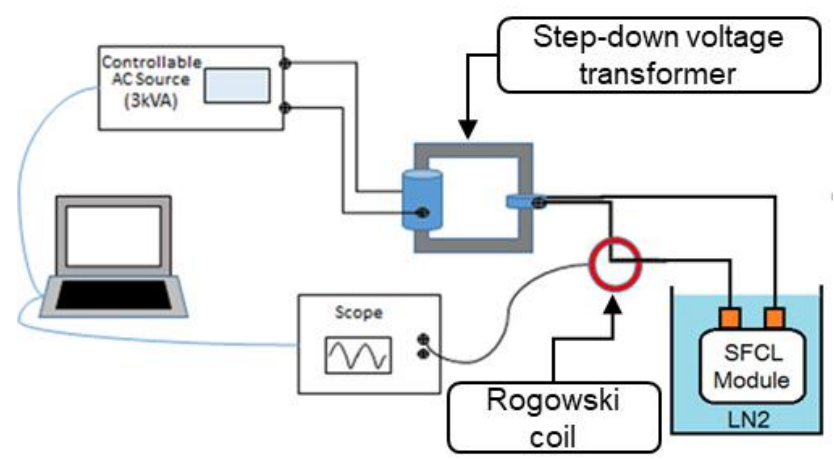

Fig. 7. Schematic of short circuit and recovery time tests applied on SFCL sample.

In the short-circuit test, the programmable $\mathrm{AC}$ voltage source supply the outlined current in the short-circuited secondary of the transformer. The current waveforms are obtained first by generating 5 cycles at, approximately, the rated current level (steady state), and after that, more 3 cycles at the fault 
current level. In order to perform the short-circuit test, the R-SFCL module acts as a short-circuit on the lower side of the transformer. The prospective currents were lower than expected due to the resistance of connections and contacts of the prototype, as well as the relatively low power of the AC source. Hence each tubular component was tested separately to achieve significative results.

For the recovery time analysis, the AC source was set following the same procedure used for the short-circuit tests. Nonetheless, after the eighth cycle, the source is turned off until $t=t_{r}$ and then it is turned on at the same levels of current as the first five cycles (nominal level). This period $\left(\mathrm{t}_{\mathrm{r}}\right)$ is decreased until each component presents a voltage response at the same level as the normal operation before the fault current limitation (the first five cycles). In this case, it is assumed that the tape recovered its initial operating condition $(77 \mathrm{~K})$, and this elapsed time it is defined as the recovery time of the component.

\section{RESULTS}

\section{A. Ix V Characterization}

Fig. 8 and 9 present the I $x \mathrm{~V}$ characteristic curve for each one of the R-SFCL components.

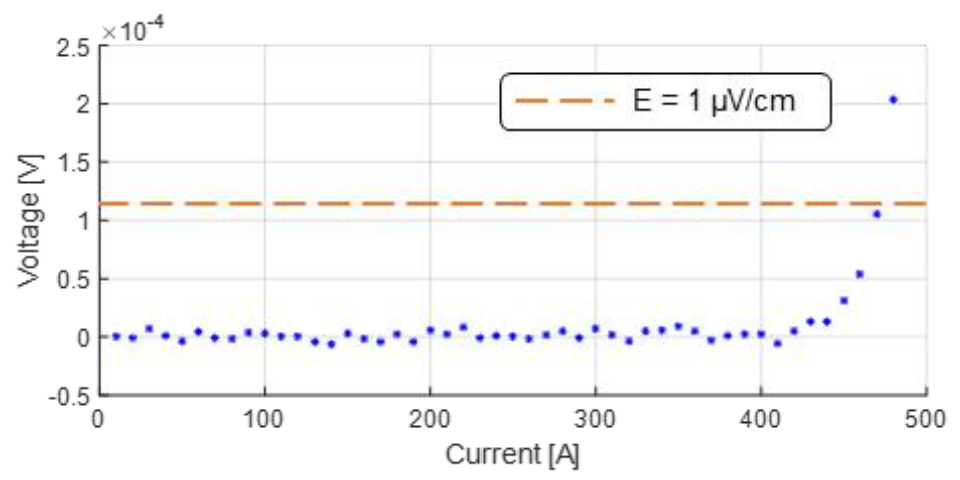

Fig. 8. I x V characteristic curve for the internal component.

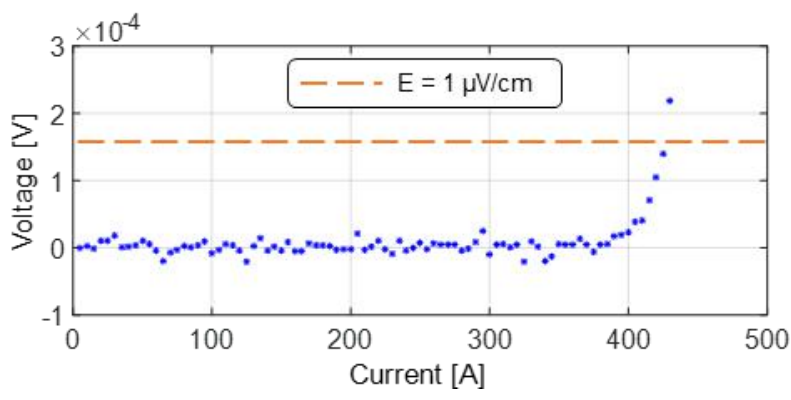

Fig. 9. I x V characteristic curve for the external component.

The R-SFCL critical current is defined by the component with the lower $\mathrm{I}_{\mathrm{c}}(430 \mathrm{~A})$. This magnitude is $28 \%$ below the expected value at ideal conditions for the two $(2 \times 297 \mathrm{~A})$. However, the current is not equally split between the two tapes in parallel in each component. In addition, the magnetic field of each tape is not totally canceled by the bifilar arrangement, so that a weak field may still influence the $I_{c}$ values. 


\section{B. Short-Circuit Tests}

This section shows the results for the short-circuit tests, following the procedure described at session III. As mentioned before, to minimize the impedance effect, each component of the prototype was analyzed separately. The AC source was set to produce $3.6 \mathrm{kA}$ (peak), with its terminals shortcircuited. However, due to the contact resistances from the connection between the source and the component and the power source available, the current levels were lower than expected. As a result, the real prospective current was $1.8 \mathrm{kA}$ (peak) to the inner component and was $1.2 \mathrm{kA}$ (peak) to the external one.

Fig. 10 presents the result of the inner component. The current limitation represents $53 \%$ on the first semi-cycle, $0.954 \mathrm{kA}$ (peak), and reached $71 \%$ on the fifth semi-cycle when compared to the fault current.

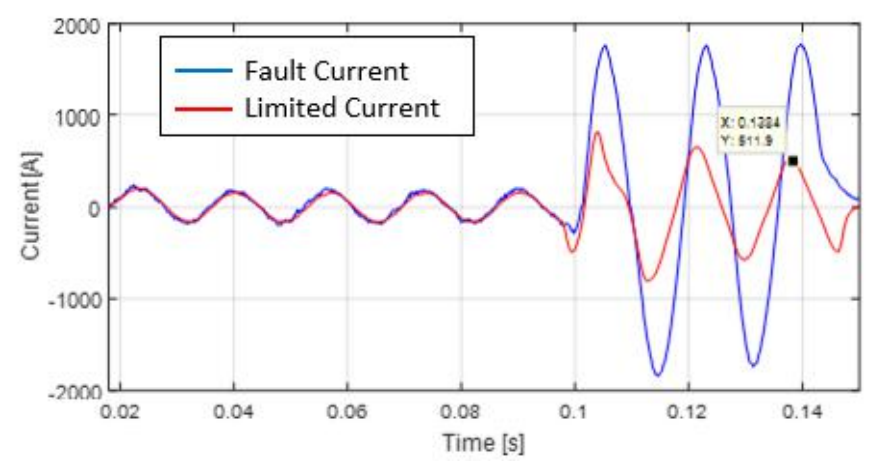

Fig. 10. The short circuit limitation for the internal component with $1.7 \mathrm{kA}$ prospective current (peak).

Again, for the external component, the prospective fault current reached $1.2 \mathrm{kA}$ (peak). The limited current presented $31 \%$ of limitation on the first semi-cycle, $0.372 \mathrm{kA}$ (peak), and $62 \%$ on the fifth semi-cycle compared to the fault current. The test result is presented in Fig. 11.

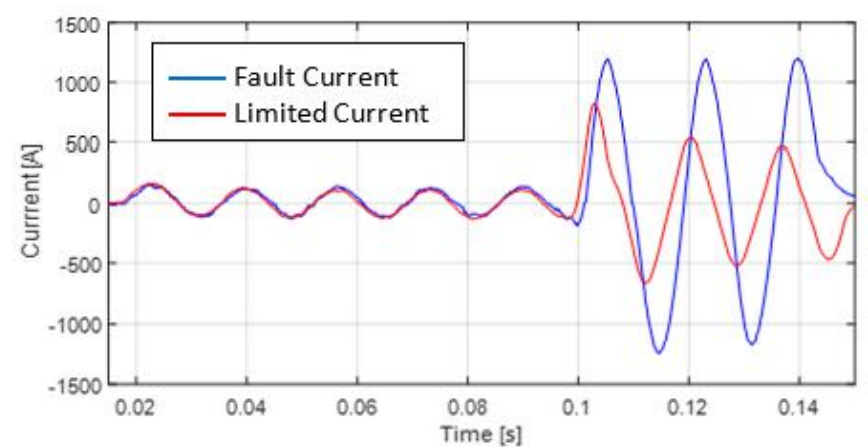

Fig. 11. The short circuit limitation results for the external component on $1.2 \mathrm{kA}$ prospective current (peak).

\section{Recovery Time Test}

This section presents the results from the recovery time analysis for each R-SFCL component. The fault current values were the same as for the short-circuit tests.

The first result concerns the internal component and it is presented in Fig. 12. In the first case, the interval between the fault event and the operation with rated current was $t_{\mathrm{rII}}=300 \mathrm{~ms}$. Then, by 
comparing the voltage and current waveforms, before the fault and after $\mathrm{t}_{\mathrm{r} 11}$, it was verified that their behavior was not the same, which means that the superconducting material does not have fully recovered. In the second case, the time interval was $t_{\mathrm{r} I 2}=310 \mathrm{~ms}$. In contrast to the first case, now the voltage and current were the same as before the fault, indicating that the material had recovered. So, the recovery time for the inner component is $\mathrm{t}_{\mathrm{r} I 2}=310 \mathrm{~ms}$.

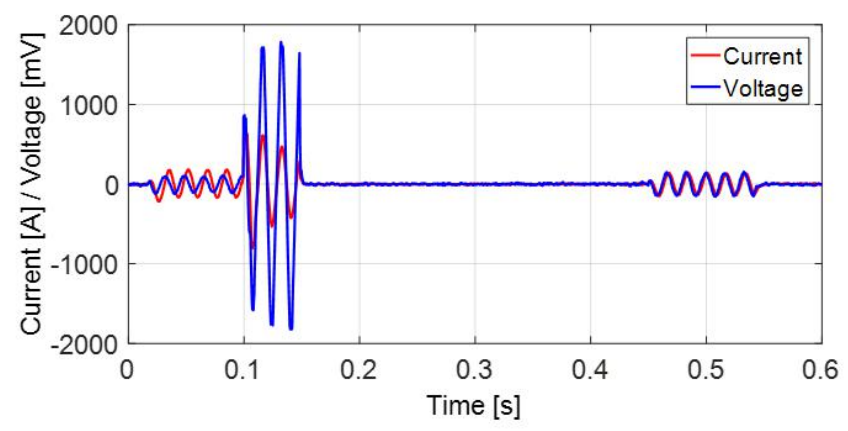

(a)

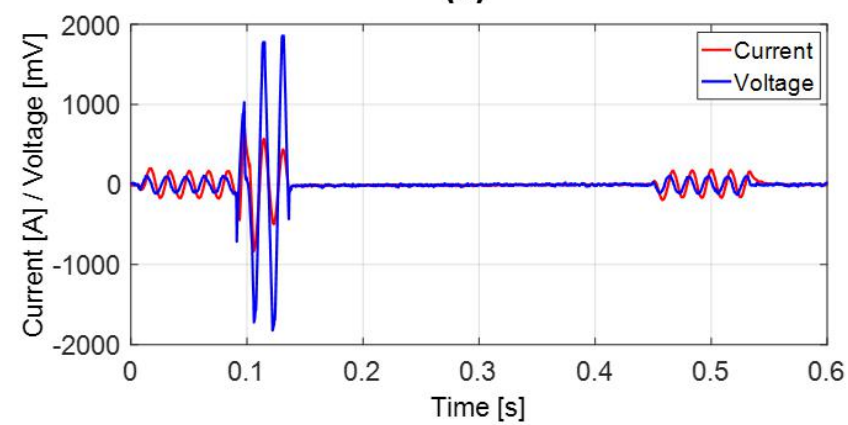

(b)

Fig. 12. Recovery time test results of R-SFCL internal component. (a) time interval $t_{\mathrm{r} I 1}=300 \mathrm{~ms}$; (b) $\mathrm{t}_{\mathrm{r} I 2}=310 \mathrm{~ms}$.

The second result is associated with the external component, Fig. 13. Again, two time periods were employed. In the first case, $\mathrm{t}_{\mathrm{rE} 1}=210 \mathrm{~ms}$. As for the inner component, by comparing the voltage and current waveforms, before the fault and after $\mathrm{t}_{\mathrm{rE} 1}$, it was verified that their behavior was not the same, which means that the superconducting material does not have fully recovered. On the second case, $\mathrm{t}_{\mathrm{rE} 2}$ $=220 \mathrm{~ms}$. Now the voltage and current were the same and they share the same angle lag. Proving that the material has fully recovered, so for the external component, the recovery time is $t_{\mathrm{rE} 2}=220 \mathrm{~ms}$. 


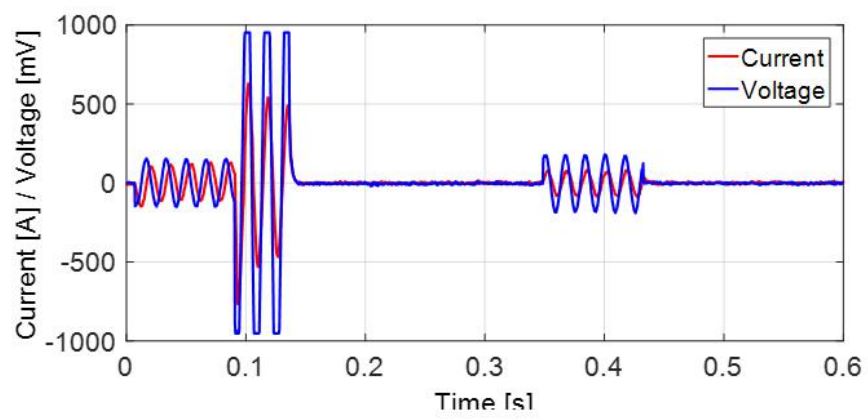

(a)

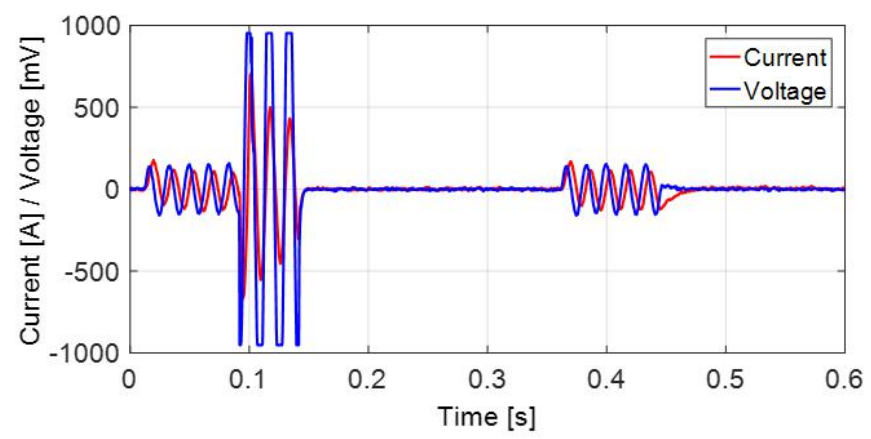

(b)

Fig. 13. Recovery time test results of R-SFCL external component. (a) recovery time $t_{\mathrm{rE} 1}=210 \mathrm{~ms}$; (b) recovery time $t_{\mathrm{rE} 2}=$ $220 \mathrm{~ms}$.

\section{CONCLUSION}

This work presented short-circuits and recovery time tests in a single phase $3 \mathrm{kVA} / 300 \mathrm{~V}$ R-SFCL prototype. A 3D printer was used to manufacture the R-SFCL holders. The short-circuit results had limited the electric current at least $30 \%$ in comparison with the prospective current. Furthermore, after $1.2 \mathrm{kA}$ short-circuit limitation, each module has recovered entirely at least $310 \mathrm{~ms}$, indicating that the heat exchange in the proposed topology is adequate.

Regarding manufacturing reproducibility, the construction process has proved to be feasible, presenting the capability to bear several thermal cycles without damage. The Acrylonitrile Butadiene Styrene (ABS) material was applied to build the R-SFCL holder. It was not observed any damage on the printed cylindrical spool after dozens of thermal cycles, suggesting it may be used as an alternative material for mounting R-SFCL prototypes. The main advantages of printing the prototype were cost, fast construction, and the fact that the designer can bring up his ideas into reality on a labscale without massive machinery.

\section{ACKNOWLEDGMENT}

The authors would like to thank the Brazilian agencies CNPq, FAPERJ and CNPq/INERGE, and the R\&D project ANEEL - LIGHT S.A. "Limitador de Corrente de Curto-Circuito Híbrido para Sistemas de Distribuição" for financially supporting the research. 


\section{REFERENCES}

[1] W. Rebizant, K. Solak, B. Brusilowicz, G. Benysek, A. Kempski, e J. Rusiński, "Coordination of overcurrent protection relays in networks with superconducting fault current limiters", Int. J. Electr. Power Energy Syst., vol. 95, pp. 307-314, fev. 2018.

[2] W. T. B. de Sousa, A. Polasek, R. Dias, C. F. T. Matt, F. A. da Silva, e R. de Andrade, "Investigation of 2G coil SCFCL - Modeling and Testing", J. Phys. Conf. Ser., vol. 507, nº 3, pp. 032005, maio 2014.

[3] W. T. Batista de Sousa, T. Mariano Lessa Assis, A. Polasek, A. M. Monteiro, e R. de Andrade, "Simulation of a Superconducting Fault Current Limiter: A Case Study in the Brazilian Power System With Possible Recovery Under Load", IEEE Trans. Appl. Supercond., vol. 26, no. 2, pp. 1-8, mar. 2016.

[4] N. Hayakawa, Y. Maeno, e H. Kojima, "Fault Current Limitation Coordination in Electric Power Grid With Superconducting Fault Current Limiters”, IEEE Trans. Appl. Supercond., vol. 28, no. 4, pp. 1-4, jun. 2018.

[5] S. Yan et al., "Design and Verification Test of a Flux-Coupling-Type Superconducting Fault Current Limiter", IEEE Trans. Magn., vol. 54, no. 11, pp. 1-5, nov. 2018.

[6] O. Krause, T. K. Saha, Y. Li, e Y. Zhao, "Current limiting impedance comparison between different designs of iron cores of the flux-lock-type superconducting fault current limiter", IET Gener. Transm. Distrib., vol. 10, no. 2, pp. 548-554, fev. 2016

[7] D. Qiu et al., "Experiment study on an inductive superconducting fault current limiter using no-insulation coils", Phys. C Supercond. Its Appl., vol. 546, pp. 1-5, mar. 2018.

[8] W. T. B. de Sousa, A. Polasek, R. Dias, C. F. T. Matt, e R. de Andrade, "Thermal-electrical analogy for simulations of superconducting fault current limiters", Cryogenics, vol. 62, pp. 97-109, jul. 2014.

[9] S. Liu, D. Xia, Z. Zhang, Q. Qiu, e G. Zhang, "Analysis of a flux-coupling type superconductor fault current limiter with pancake coils", Cryogenics, vol. 87, pp. 18-23, out. 2017.

[10] J. Sheng et al., "Study of recovery characteristics of 2nd generation HTS tapes with different stabilizers for resistive type superconducting fault current limiters", Phys. C Supercond. Its Appl., vol. 521-522, pp. 33-37, fev. 2016.

[11]A. T. Queiroz et al., "Simulation of resistive superconducting fault current limiter in ATPDraw", in 2018 Simposio Brasileiro de Sistemas Eletricos (SBSE), Niteroi, 2018, pp. 1-5.

[12] W. T. B. de Sousa, O. Nackel, e M. Noe, "Transient Simulations of an Air-Coil SFCL", IEEE Trans. Appl. Supercond., vol. 24, no. 4, pp. 1-7, ago. 2014.

[13] W. T. B. de Sousa, A. Polasek, T. M. L. Assis, R. de Andrade, e M. Noe, "Simulations of Resistive and Air Coil SFCLs in a Power Grid", IEEE Trans. Appl. Supercond., vol. 25, no. 3, pp. 1-5, jun. 2015.

[14]X. Pei, X. Zeng, A. C. Smith, e D. Malkin, "Resistive superconducting fault current limiter AC loss measurements and analysis", IEEE Trans. Appl. Supercond., pp. 1-1, 2016.

[15] W. T. B. de Sousa, A. Polasek, F. A. Silva, R. Dias, A. R. Jurelo, e R. de Andrade, "Simulations and Tests of MCPBSCCO-2212 Superconducting Fault Current Limiters”, IEEE Trans. Appl. Supercond., vol. 22, no. 2, pp. 56001065600106, abr. 2012.

[16]Z. Hong, J. Sheng, L. Yao, J. Gu, e Z. Jin, “The Structure, Performance and Recovery Time of a 10 kV Resistive Type Superconducting Fault Current Limiter", IEEE Trans. Appl. Supercond., vol. 23, no. 3, pp. 5601304-5601304, jun. 2013. [17] W. T. B. de Sousa, A. Polasek, C. F. T. Matt, e R. de Andrade, "Recovery of Superconducting State in an R-SCFCL MCP-BSCCO-2212 Assembly”, IEEE Trans. Appl. Supercond., vol. 23, no. 1, pp. 5601407-5601407, fev. 2013.

[18]H. Sun et al., "Insulation Characteristics of Polyimide as Insulation Material Used in Pancake Tape Coil Structure for Resistive-Type SFCL”, IEEE Trans. Appl. Supercond., vol. 25, no. 3, pp. 1-4, jun. 2015.

[19] N. Hayakawa, K. Ishida, M. Mimbu, H. Kojima, S. Isojima, e M. Kuwata, "Volume Effect of Dynamic Breakdown Strength in LN2 for Insulation Design of Resistive Superconducting Fault Current Limiters", IEEE Trans. Appl. Supercond., vol. 28 , no. 4, pp. 1-4, jun. 2018.

[20]W. T. B. de Sousa et al., "Short-Circuit Tests and Simulations with a SCFCL Modular Assembly", Phys. Procedia, vol. 36 , pp. 1242-1247, 2012.

[21]H. J. Schettino, R. de Andrade Jr, A. Polasek, D. Kottonau, e W. T. B. de Sousa, “A strategy for protection of high voltage systems using resistive superconducting fault current limiters", Phys. C Supercond. Its Appl., vol. 544, pp. 40-45, jan. 2018.

[22] A. Polasek, R. Dias, E. T. Serra, O. O. Filho, e D. Niedu, "Short-circuit testing of monofilar Bi-2212 coils connected in series and in parallel", J. Phys. Conf. Ser., vol. 234, no. 3, pp. 032048, jun. 2010.

[23] SuperPower, "Wire Specification”, SuperPower ${ }^{\circledR 2}$ G HTS Wire Specifications, 2018. [Online]. Disponível em: http://www.superpower-inc.com/content/wire-specification. [Acessado: 04-dez-2018].

$[24]$ K. Bauml e S. Grosmann, "Investigations on Different Joining Techniques Regarding Electrical Joints With Normal Conducting Material and YBCO Coated Conductors", IEEE Trans. Appl. Supercond., vol. 26, no. 3, pp. 1-5, abr. 2016. [25]N. Bagrets, A. Augieri, G. Celentano, G. Tomassetti, K.-P. Weiss, e A. della Corte, "Investigation of ReBCO Conductor Tape Joints for Superconducting Applications", IEEE Trans. Appl. Supercond., vol. 25, no. 3, pp. 1-5, jun. 2015. [26] Hyoungku Kang et al., "Development of a 13.2 kV/630 A (8.3 MVA) High Temperature Superconducting Fault Current Limiter”, IEEE Trans. Appl. Supercond., vol. 18, no. 2, pp. 628-631, jun. 2008. 